\title{
Predicting Medical Students' Intention to Integrate Digital Health into their Medical Practice: A Pre- and Post-COVID-19 Survey in Canada
}

\author{
Guy Paré \\ HEC Montréal \\ guy.pare@hec.ca \\ Marie-Pascale Pomey \\ Université de Montréal \\ marie-pascale.pomey@umontreal.ca
}

\author{
Louis Raymond \\ Université du Québec à Trois-Rivières \\ louis.raymond@uqtr.ca \\ Geneviève Grégoire \\ Université de Montréal \\ genevieve.gregoire.1@umontreal.ca
}

\begin{abstract}
In recent years, many stakeholders have advocated digital health (dHealth) as a promising avenue to reduce inefficiencies, increase the accessibility and quality of care, and manage infectious diseases. In this context, an emerging issue for researchers and practitioners lies in the dHealth education and training that must be provided to medical students to prepare them to make effective use of dHealth technologies, and of artificial intelligence (AI) in particular, in their future medical practice. In addressing this issue, this paper aims to validate a theoretical model that hypothesizes relationships between medical students' individual background, experimentation with dHealth, perceived dHealth education needs, and openness to AI-related innovations. To do so, a two-phased survey study of Canadian medical students was realized. Results confirming all but one of the research hypotheses thus constitute a valid basis for prediction and prescription with regard to the students' integration of dHealth into their medical practice.
\end{abstract}

\section{Introduction}

The Canadian Medical Association (CMA) [1] believes that digital technologies will particularly revolutionize the delivery of health care in Canada on three fronts: virtual care, which represents an alternative to in-person care, big health data, which includes multiple applications such as AI, precision medicine, and population health management, and, finally, technological advances such as mobile applications, robotics, 3D printing, augmented reality, virtual reality and the internet of things (IoT). As another clear indication of the growing importance of digital health (dHealth), Health Canada created in 2018 a dedicated dHealth division within the Medical Devices Bureau of the Therapeutic Products Directorate. The mission of this division is related to the focused pre-market review of dHealth technologies, with the goal of tracking rapid cycles of innovation.
For the practice of medicine to improve through the anticipated benefits of digital technologies, future generations of physicians must be able to navigate with ease in an ever-changing technological environment, in addition to effectively collaborating with computer science specialists [2]. To this end, the literature teaches us that the training of medical students is an important factor in the adoption of dHealth technologies such as telemedicine and that the interaction of future health professionals with such technologies during their training allows the development of basic patient care competencies as well as medical knowledge [3].

Chandrashekar [2] argues that medical schools integrate dHealth little or not at all into the training of future health professionals, which poorly prepares them for the changing reality of clinical practice $[4,5]$, notwithstanding that the actors involved in updating curricula consider dHealth to be relevant and important [6]. According to Lam et al. [7], this underexposure causes medical and health sciences students to have limited understanding of dHealth. Insufficient training is also prone to lead to bad behavior in students (e.g., violation of patient confidentiality), which can ultimately lead to severe legal consequences [8].

Aware of this reality, both the Association of Faculties of Medicine of Canada (AFMC) and Canada Health Infoway have issued recommendations regarding the competencies expected of medical students with regard to dHealth. These competencies, based on the CanMEDS 2015 framework [9], are subdivided according to the students' background (preclinical and internship) and are meant to better prepare them for the practice of modern medicine. Through several other partnerships aimed at encouraging the integration of dHealth into medical training, Canada Health Infoway participated in the implementation of several tools such as a prototype online toolkit on dHealth for teachers, a dHealth webinar series and an electronic medical records (EMR) guide. Despite these efforts, the integration of dHealth into the curricula of medical schools in Canada seems to be progressing slowly [10] and it is estimated that 
several years will be necessary before one can offer virtual care comparable to those offered within private health systems such as Kaiser Permanente [11].

In this context, we conducted a two-phased survey study of medical students in Canada, aiming to answer the following research questions: What are medical students' attitude and intention regarding the integration of dHealth into their future medical practice? What are the main antecedent factors of medical students' attitude and intention? Given the present dearth of knowledge on these questions and their increased relevance in the context of the Covid-19 pandemic [12], the present study's intended contribution to dHealth research and practice lies in a clear and parsimonious characterization and explanation of the role, place, and future impacts of dHealth technologies in medical education.

\section{Theoretical Background}

The main theoretical foundation of this study is Ajzen's theory of planned behavior (TPB), which has been often-used to study health-related behaviors [e.g., 13]. This theory postulates that the behavioral intention of individuals is mainly determined by their attitude toward the behavior, subjective norm, and perceived behavioral control, which in turn may be influenced by individual and social background factors [14].

This theorization is complemented by postulating the 'perceived facilitating conditions' concept (instead of perceived behavioral control) to be a critical determinant of attitude and behavioral intention [15]. Originating in the technology acceptance model (TAM), facilitating conditions (e.g., availability of training) are external control factors that positively influence an individual's perception of the difficulty with which a task (e.g., making effective use of dHealth technologies) may be performed [e.g., 16, 17].

The theoretical framework is completed by including the 'individual absorptive capacity' concept (instead of subjective norm) as an added explanatory factor of attitude and intention. Absorptive capacity (ACAP) is defined as individuals' ability to absorb, that is, to acquire, assimilate, transform, and exploit new knowledge in their environment [18]. This concept originates in theory which postulates that absorptive capacity positively influences an individual's attitude and intention with regard to innovative behavior such as adopting a new technology [19].

The theoretical model to be empirically validated in this study is presented in Figure 1. Following a review

\footnotetext{
1 This review cannot be presented due to space limitations.

2 The medical students' attitude was conceptualized and operationalized regarding AI specifically rather than dHealth
}

of the literature on medical education and training in dHealth [e.g., 2-8, 10, 20, 21, 22], ${ }^{1}$ our theoretical constructs, namely individual absorptive capacity, perceived facilitating conditions, attitude, and intention were operationalized respectively as four variables directly pertaining to our research questions and objectives, namely experimentation with dHealth, perceived dHealth education needs, openness to AIrelated technologies ${ }^{2}$, and intention to integrate dHealth into the medical practice. A fifth theoretical construct, individual background, was operationalized as a composite of four student characteristics (age, gender, academic level, and health self-tracking behavior).

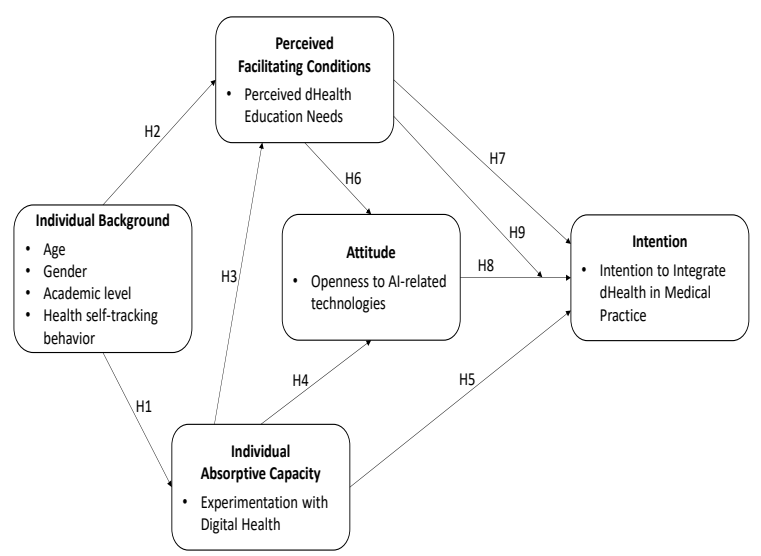

Figure 1. Theoretical Model and Hypotheses

Given the relationships postulated by the three theoretical lenses mobilized in this study as well as the empirical relationships identified in the extant literature, the following hypotheses were formulated in the form of a theoretical model. The first two hypotheses emanate from the TAM and ACAP theory wherein IT users' individual background is deemed to influence their absorptive capacity and perceptions of the conditions facilitating their use of IT:

H1: Medical students' individual background will influence the extent of their experimentation with dHealth technologies.

H2: Medical students' individual background will influence the extent of their perceived dHealth education needs.

For its part, hypothesis 3 emanates from ACAP theory wherein IT users' absorptive capacity is deemed to positively influence their perceptions of facilitating conditions:

technologies generally, as AI is the dHealth technology that has the most potential to fundamentally alter and significantly improve the practice of medicine $[20,21,22]$. 
H3: The greater the medical students' experimentation with dHealth technologies, the greater their perceived dHealth education needs.

Hypothesis 4 is based on ACAP theory and TPB wherein IT users' absorptive capacity is deemed to positively influence their attitude and behavioral intention with regard to dHealth use:

H4: The greater the medical students' experimentation with dHealth, the greater their openness to AIrelated technologies.

H5: The greater the medical students' experimentation with dHealth, the greater their intention to integrate dHealth into their medical practice.

The next two hypotheses emanate from the TAM and the TPB wherein IT users' perceptions of facilitating conditions are deemed to positively influence their attitude and behavioral intention:

H6: The greater the medical students' perceived dHealth education needs, the greater their openness to AIrelated technologies.

H7: The greater the medical students' perceived dHealth education needs, the greater their intention to integrate dHealth into their medical practice.

Hypothesis 8 is derived from the TPB wherein IT users' attitude is deemed to positively influence their behavioral intention:

H8: The greater the medical students' openness to AIrelated technologies, the greater their intention to integrate dHealth into their medical practice.

The final hypothesis also originates from TPB and TAM wherein IT users' perceptions of facilitating conditions are deemed to moderate the relationship between their attitude and behavioral intention:

H9: The medical students' perceived dHealth education needs will moderate the relationship between their openness to AI-related technologies and their intention to integrate dHealth into their medical practice.

\section{Methods}

Empirical data were obtained from a Web-based survey using the Qualtrics platform, administered in two phases, that is, an initial survey $\left(\mathrm{t}_{0}\right)$ in February 2020, before the Covid-19 pandemic, and a replication survey $\left(\mathrm{t}_{1}\right)$ in January 2021, during the pandemic. The survey population consisted of the 1,367 medical school students at the University of Montreal. The survey questionnaire, approved by the university's ethics committee, was pretested with 10 medical students who were thus excluded from the sampling population. A total of 184 students fully responded to the initial survey (13\%), whereas 138 fully responded to the replication survey (10\%). The profile of the anonymous respondents is presented in Table 1.

The measurement of the research variables was based on the previously mentioned review of the literature on medical education in dHealth. Table 2 provides essential information on the questionnaire's content. Measuring the research variables through a self-administered questionnaire with a single respondent poses a risk of common method bias (CMB) [23]. As precautionary measures, we chose different question formats and scale types. Further, we examined the correlation matrix of the five research constructs to determine if any two constructs correlated above 0.90 , as this could signal the presence of CMB in the data [24]. In our case, all construct correlations were wellbelow this threshold. We also employed Harman's single-factor test to check for $\mathrm{CMB}$, examining the unrotated factor solution for all variables in the measurement model. As multiple factors emerged from the factor analysis and as no single factor accounted for $50 \%$ or more of the covariance among the variables, this further suggests the absence of CMB [25].

\section{Table 1. Profile of the respondents}

\begin{tabular}{|c|c|c|c|c|c|}
\hline \multirow{2}{*}{\multicolumn{2}{|c|}{$\begin{array}{l}\text { Medical students' } \\
\text { individual background }\end{array}$}} & \multicolumn{2}{|c|}{$\mathbf{t}_{0}(\mathrm{n}=184)$} & \multicolumn{2}{|c|}{$\mathbf{t}_{\mathbf{1}}(\mathrm{n}=138)$} \\
\hline & & \multirow{2}{*}{$\frac{\mathbf{N}}{40}$} & \multirow{2}{*}{$\begin{array}{c}\% \\
22 \%\end{array}$} & \multirow{2}{*}{$\frac{\mathbf{N}}{28}$} & \multirow{2}{*}{$\begin{array}{c}\% \\
20 \%\end{array}$} \\
\hline \multirow{5}{*}{$\begin{array}{l}\text { Academic } \\
\text { level }\end{array}$} & $\begin{array}{l}\text { preparatory } \\
\text { year }\end{array}$ & & & & \\
\hline & $\begin{array}{l}1^{\text {st }} \text { year } \\
\text { preclinical }\end{array}$ & 36 & $20 \%$ & 32 & $23 \%$ \\
\hline & $\begin{array}{l}2^{\text {nd }} \text { year } \\
\text { preclinical }\end{array}$ & 43 & $23 \%$ & 55 & $40 \%$ \\
\hline & $\begin{array}{l}1^{\text {st }} \text { year } \\
\text { internship }\end{array}$ & 33 & $19 \%$ & 8 & $6 \%$ \\
\hline & $\begin{array}{l}2^{\text {nd }} \text { year } \\
\text { internship }\end{array}$ & 32 & $17 \%$ & 14 & $10 \%$ \\
\hline \multirow{2}{*}{ Gender } & female & 119 & $65 \%$ & 92 & $70 \%$ \\
\hline & male & 65 & $35 \%$ & 40 & $30 \%$ \\
\hline \multirow{2}{*}{$\begin{array}{l}\text { Health } \\
\text { self- } \\
\text { tracking }\end{array}$} & no & 151 & $82 \%$ & 105 & $76 \%$ \\
\hline & yes & 33 & $18 \%$ & 33 & $24 \%$ \\
\hline \multirow{4}{*}{ Age } & mean & \multicolumn{2}{|c|}{22.9} & \multicolumn{2}{|c|}{22.6} \\
\hline & std. dev. & \multicolumn{2}{|c|}{3.5} & \multicolumn{2}{|c|}{2.7} \\
\hline & minimum & \multicolumn{2}{|c|}{18} & \multicolumn{2}{|c|}{18} \\
\hline & maximum & \multicolumn{2}{|c|}{38} & \multicolumn{2}{|c|}{35} \\
\hline
\end{tabular}

The data were first analyzed through descriptive statistics and further examined through analyses of variance and principal component analyses, using the IBM SPSS software v27. Component-based structural equation modeling (SEM) was then used to test the research hypotheses (cf. Figure 1). As implemented in the SmartPLS software, the PLS (partial least squares) 
technique was chosen for its robustness with regard to the distribution of residuals and its greater affinity for exploratory rather than confirmatory research purposes when compared to covariance-based SEM techniques such as AMOS and EQS [26].

\section{Results}

The results of the initial study $\left(\mathrm{t}_{0}\right)$ are first presented, followed by - and compared with - the results of the replication study $\left(\mathrm{t}_{1}\right)$.

\subsection{Descriptive analysis $\left(t_{0}\right)$}

For analytical purposes, individual dHealth technologies and applications were first grouped under five technology "bundles" that were named basic IT systems (e.g., electronic medical records, clinical information systems), advanced dHealth (e.g., robotics, virtual reality), telehealth (teleconsultation, tele- expertise), AI-related technologies (e.g., artificial intelligence, machine learning) and mobile applications (e.g., UpToDate, BMJBestPractice). The descriptive statistics and indices of reliability of the research variables are presented in Table 2 . The descriptive analysis of the data leads us to make the following observations:

- A large majority of the sampled medical students have had little or no exposure to advanced dHealth, telehealth, and AI-related technologies in the course of their medical training. However, a minority report having been somewhat exposed to basic IT systems $(\approx 33 \%)$ and mobile applications $(\approx 20 \%)$.

- As expressed by more than half of the students, their most important dHealth education needs mainly concern, by order of importance, basic IT systems, telehealth, and AI-related technologies. About $45 \%$ of respondents, however, perceive no true need concerning advanced dHealth technologies.

Table 2. Reliability and descriptive statistics of the research variables $\left(\mathrm{t}_{0}, \mathrm{n}=184\right)$

\begin{tabular}{|c|c|c|c|c|c|c|}
\hline $\begin{array}{l}\text { Research Construct } \\
\text { Research variable }\end{array}$ & $\alpha^{\mathbf{a}}$ & VIF $^{\mathbf{b}}$ & mean & st.dev. & min. & $\max$ \\
\hline \multicolumn{7}{|l|}{ Individual Background } \\
\hline Age (yrs.) & - & 1.11 & 23 & 3 & 18 & 38 \\
\hline Gender ( 0 : male, 1 : female) & - & 1.02 & 0.65 & - & 0 & 1 \\
\hline Academic level ${ }^{\mathrm{c}}$ & - & 1.12 & 2.9 & 1.3 & 1 & 5 \\
\hline Health self-tracking behavior ( $0:$ no, $1:$ yes $)$ & - & 1.02 & 0.18 & - & 0 & 1 \\
\hline \multicolumn{7}{|l|}{ Experimentation with dHealth } \\
\hline With basic IT systems ${ }^{\mathrm{d}}$ & 0.86 & - & 1.8 & 0.8 & 1.0 & 4.6 \\
\hline With advanced dHealth ${ }^{\mathrm{d}}$ & 0.88 & - & 1.2 & 0.7 & 1.0 & 4.0 \\
\hline With telehealth ${ }^{\mathrm{d}}$ & 0.78 & - & 1.2 & 0.8 & 1.0 & 4.0 \\
\hline With AI-related technologies ${ }^{\mathrm{d}}$ & 0.84 & - & 1.3 & 0.4 & 1.0 & 4.0 \\
\hline With mobile applications ${ }^{\mathrm{e}}$ & 0.88 & - & 1.5 & 0.5 & 1.0 & 3.3 \\
\hline \multicolumn{7}{|l|}{ Perceived dHealth Education Needs } \\
\hline On basic IT systems ${ }^{f}$ & 0.93 & - & 4.1 & 0.8 & 2.4 & 5.0 \\
\hline On advanced dHealth technologies ${ }^{\mathrm{f}}$ & 0.93 & - & 3.4 & 0.7 & 1.0 & 5.0 \\
\hline On telehealth ${ }^{\mathrm{f}}$ & 0.86 & - & 3.7 & 0.8 & 1.0 & 5.0 \\
\hline On AI-related technologies ${ }^{\mathrm{f}}$ & 0.84 & - & 3.5 & 0.7 & 1.5 & 5.0 \\
\hline \multicolumn{7}{|l|}{ Openness to AI-related Technologies } \\
\hline For the medical profession ${ }^{g}$ & 0.82 & - & 3.6 & 0.6 & 2.0 & 5.0 \\
\hline For the medical specialties ${ }^{\mathrm{h}}$ & 0.82 & - & 3.4 & 0.5 & 2.3 & 5.0 \\
\hline For their medical practice ${ }^{i}$ & - & - & 3.9 & 3.3 & 0.0 & 8.0 \\
\hline \multicolumn{7}{|l|}{ Intent to Integrate dHealth in Medical Practice } \\
\hline For patient communication and consultation ${ }^{\mathrm{j}}$ & 0.94 & - & 3.4 & 1.4 & 1.0 & 5.0 \\
\hline For patient monitoring and follow-up ${ }^{\mathrm{j}}$ & 0.91 & - & 3.3 & 1.4 & 1.0 & 5.0 \\
\hline For disease prevention, diagnosis and treatment $\mathrm{t}^{\mathrm{j}}$ & 0.95 & - & 3.6 & 1.5 & 1.0 & 5.0 \\
\hline \multicolumn{7}{|c|}{ 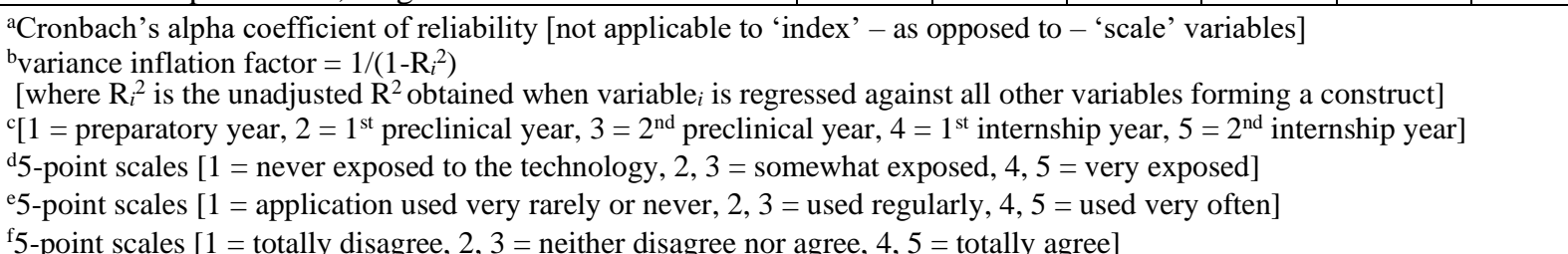 } \\
\hline
\end{tabular}




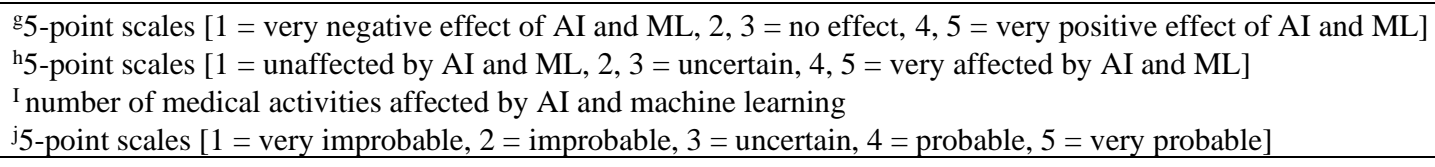

- More than half of the sampled medical students are observed to have an open attitude toward AI-related technologies, be it in terms of these technologies' effect on the medical profession $(\approx 66 \%)$, on the medical specialties $(\approx 55 \%)$, and on their own medical practice $(\approx 55 \%)$. Moreover, $70 \%$ of students indicate that they expect to use AI-related technologies in support of one or more of their future medical activities such as image and data analysis, diagnosis, and prognosis.

- A large majority of students declare an intention to integrate dHealth into their medical practice. This intention is most important with regard to disease prevention, diagnosis, and treatment $(\approx 75 \%)$, followed by patient communication and consultation $(\approx 65 \%)$, and patient monitoring and follow-up $(\approx 60 \%)$.

\subsection{Causal analysis $\left(t_{0}\right)$}

As presented in Figure 2, the causal paths inferred from the conceptual framework were tested by assessing the path coefficients ( $\beta$ ) estimated by the SEM procedure as executed by the SmartPLS software. The performance of the theoretical model that interrelates the five research constructs is indicated by the strength and significance of the $\beta \mathrm{s}$ and the proportion of explained variance $\left(\mathrm{R}^{2}\right)$, as befits PLS's focus on prediction and concern with generalization [27].

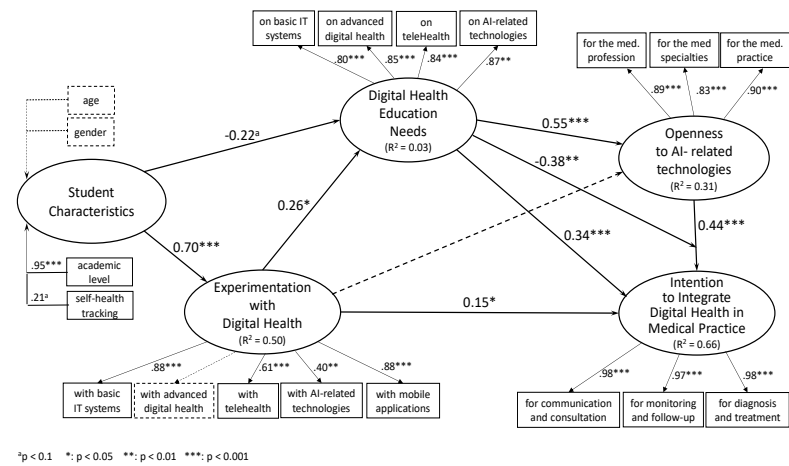

Figure 2. Causal analysis results

In this study, whereas one research construct (Individual Background) is modeled as being "formative" given its composite and multidimensional nature, the four other constructs are modeled as being "reflective" (cf. Figure 2) [28]. The first step in the data analysis consists of simultaneously estimating the measurement and theoretical models, using the PLSSEM technique. The metric properties of the five research constructs are thus assessed within the context of the theoretical model. As the standard reliability and validity criteria applicable to reflective constructs do not apply to formative constructs, one must first verify that there is no collinearity among the formative construct's indicators. To do so, one uses the variance inflation factor (VIF) statistic, the rule being that the VIF must not be greater than 3.3 [28]. As seen in Table 2, the VIF value for the four formative indicators of the construct is below this threshold, confirming the absence of collinearity.

Having assessed the validity of the formative measure, the unidimensionality, reliability, predictive validity, and discriminant validity of the four reflective constructs must then be evaluated. The unidimensionality of a reflective measure is assessed by looking at each of its indicators' loading $(\lambda)$, the threshold being 0.40 for newly developed scales [29]. As the "with advanced dHealth" indicator of the Experimentation with dHealth construct did not meet this threshold, it was removed from the measure to insure its unidimensionality (cf. Figure 2). Furthermore, composite reliability coefficient values above the 0.70 threshold, confirm the internal consistency of the four reflective constructs. There is also evidence of the convergent validity of these constructs because their average variance extracted (AVE) is above the 0.50 threshold (see Table 2).

The last property to be verified is discriminant validity, showing the extent to which each research construct, as measured, is unique and different from the others. In the case of the formative construct, the fact that it shares less than $50 \%$ variance with any other construct (inter-construct correlation inferior to 0.71 ) is evidence of such validity [30]. For the four reflective constructs, discriminant validity is verified when the variance shared by each with any other construct is less than its AVE, which is the case here.

Hypothesis 1 (partly confirmed). Given the results of the initial causal analysis $\left(\mathrm{t}_{0}\right)$ provided by the SEM procedure, an initial finding lies in the positive and highly significant path coefficient that links the medical students' characteristics to their experimentation with dHealth technologies and applications $(\beta=0.70, p<$ 0.001). As expected, the primary explanatory characteristic is the academic level, as students who are in their internship years have had greater opportunity to experiment with dHealth technologies and applications than those who are in their preparatory or preclinical years. 
Hypothesis 2 (partly confirmed). Another related finding is that the medical students' characteristics are negatively and significantly associated to their dHealth education needs $(\beta=-0.22, p<0.1)$. Here again, the primary explanatory characteristic is the academic level, as students in their preparatory or preclinical years express more important needs than those in their internship years. One may surmise that the more advanced students, having experimented more with various dHealth technologies and applications, are more realistic as to their education needs and thus have less expectations in this regard.

Hypothesis 3 (confirmed). A third finding regards the positive influence of the medical students' experimentation with dHealth technologies on their dHealth education needs $(\beta=0.26, p<0.05)$. In other words, developing a greater absorptive capacity with regard to dHealth allows these individuals to better understand the conditions that facilitate the integration of dHealth in the practice of medicine. And considering dHealth education as one of the most important facilitating conditions, greater practical experience with dHealth technologies and applications would lead students to express greater needs for such education within their medical curriculum.

Hypothesis 4 (unconfirmed). Returning to Figure 2, no direct relationship was found between the medical students' experimentation with dHealth and their openness to AI-related technologies $(\beta=0.07, \mathrm{p}=$ $0.209)$. This may be due here to the intrinsic nature of the experimentation measure, as it includes technology bundles other than the AI-related technologies bundle.

Hypothesis 5 (partly confirmed). We did find a positive and significant influence of the students' experimentation with dHealth technologies and applications on the students' intention to integrate dHealth into their medical practice $(\beta=0.15, \mathrm{p}<0.05)$.

Table 3. Comparison of research variable means between $t_{0}$ and $t_{1}$

\begin{tabular}{|c|c|c|c|}
\hline $\begin{array}{l}\text { Research Construct } \\
\text { Research variable }\end{array}$ & $\begin{array}{c}\mathbf{t}_{\mathbf{0}} \\
(\mathrm{n}=184) \\
\text { mean }\end{array}$ & $\begin{array}{c}\mathbf{t}_{\mathbf{1}} \\
(\mathrm{n}=138) \\
\text { mean }\end{array}$ & $\begin{array}{c}\text { T-test } \\
\text { (two-tailed) }\end{array}$ \\
\hline \multicolumn{4}{|l|}{ Individual Background } \\
\hline Age & 22.9 & 22.6 & 1.0 \\
\hline Gender & 0.65 & 0.70 & -0.9 \\
\hline Academic level & 2.9 & 2.6 & 1.9 \\
\hline Self-health tracking behavior & 0.18 & 0.24 & -1.3 \\
\hline \multicolumn{4}{|l|}{ Experimentation with dHealth } \\
\hline With basic IT systems & 1.8 & 1.4 & $4.2 * * *$ \\
\hline With advanced dHealth & 1.2 & 1.1 & $2.4^{*}$ \\
\hline With telehealth & 1.2 & 1.5 & $-4.6 * * *$ \\
\hline With AI-related technologies & 1.3 & 1.2 & 2.0 \\
\hline With mobile applications & 1.5 & 1.3 & $3.6 * * *$ \\
\hline \multicolumn{4}{|l|}{ Perceived dHealth Education Needs } \\
\hline On basic IT systems & 4.1 & 4.1 & 0.3 \\
\hline On advanced dHealth & 3.4 & 3.4 & -0.1 \\
\hline On telehealth & 3.7 & 4.1 & $-5.0 * * *$ \\
\hline On AI-related technologies & 3.5 & 3.5 & 0.3 \\
\hline \multicolumn{4}{|l|}{ Openness to AI-related Technologies } \\
\hline For the medical profession & 3.6 & 3.5 & 1.2 \\
\hline For the medical specialties & 3.4 & 3.3 & 0.8 \\
\hline For the medical practice & 3.9 & 3.6 & 0.8 \\
\hline \multicolumn{4}{|l|}{ Intent to Integrate dHealth in Medical Practice } \\
\hline For patient communication and consultation & 3.4 & 3.3 & 0.6 \\
\hline For patient monitoring and follow-up & 3.3 & 3.1 & 1.5 \\
\hline For disease prevention, diagnosis and treatment & 3.6 & 3.3 & $2.1 *$ \\
\hline \multicolumn{4}{|l|}{$*: \mathrm{p}<0.05 \quad * * *: \mathrm{p}<0.001$} \\
\hline
\end{tabular}

This result is in line with ACAP theory which postulates that an individual's greater capacity to assimilate and exploit IT-related knowledge is associated to more innovative behavior with regard to IT [31]. Experimenting with dHealth technologies within their medical curriculum would thus spur the students' intention to integrate these technologies in their future practice. Now, given that the path coefficient is inferior to 0.20 and the indirect effects of experimenting with dHealth on the students' intention (through their 
dHealth education needs and openness to AI) are greater than the direct effects, this last finding is rather tentative and calls for further verification.

Hypotheses 6 and 7 (confirmed). Other important results of the causal analysis lie in the positive and highly significant relationship of the medical students' dHealth education needs both with their openness to AIrelated technologies $(\beta=0.55, \mathrm{p}<0.001)$ and with their intention to integrate $\mathrm{dHealth}$ in their medical practice $(\beta=0.34, p<0.001)$. These two findings are in line with the extended TAM (technology acceptance model) [17] and extended UTAUT (unified theory of acceptance and use of technology) [32] behavioral theories. This result thus comforts our theoretical assumption that the medical students' dHealth education needs may be viewed as facilitating conditions that positively influence their attitude toward AI-related technologies and their behavioral intention with regard to dHealth technologies.

Hypothesis 8 (confirmed). The next finding lies in the positive and highly significant path coefficient $(\beta=$ $0.44, \mathrm{p}<0.001)$ that links the medical students' openness to AI-related technologies to their intention to integrate dHealth into their medical practice. This last result is in line with the IT behavioral theory, originating in the extended TAM, that links individuals' attitudes towards IT to their behavioral intention with regard to IT [33]. As such, openness to AI-related technologies may thus be considered as an added facilitating condition for the integration of dHealth technologies in medical practice $[17,32]$.

Hypothesis 9 (confirmed). The study's final finding lies in the negative and significant path coefficient $(\beta=$ $-0.34, p<0.01)$ that confirms the moderating effect of the students' perceived dHealth education needs on the relationship between their openness to AI-related technologies and their intention to integrate dHealth into their medical practice. In other words, when their dHealth education needs are high, their openness to AI has a lesser influence on their intention. Conversely, when their needs are low, their openness to AI has a greater influence on their intention. This last result is also in line with previous TPB-based studies that found perceived behavioral control to have a moderating effect on the relationship between attitude and intention [34].

\subsection{Descriptive analysis $\left(t_{1}\right)$}

The descriptive statistics and indices of reliability of the research variables for the replication study $\left(t_{1}\right)$ were compared with those of the initial study $\left(\mathrm{t}_{0}\right)$. These results first indicate that the research variables' reliability (Cronbach's $\alpha$ coefficient) is confirmed anew. Second, when comparing the variable means between the two studies, and as presented in Table 3, analyses of variance confirm highly significant $(\mathrm{p}<0.001)$ differences on four of the research variables. First, medical students in the replication study have, on average, experimented more with telehealth technologies and, conversely, have experimented less with basic IT systems and mobile applications than those in the initial study. Second, the former group of students expressed a greater need for education on telehealth technologies than the latter. Moreover, this need is the first one by order of importance for the students in the replication study, whereas it is the second one for those in the initial study. Here, one may tentatively explain these differences by the advent of the Covid-19 pandemic, which has brought teleconsultation and telemedicine to the forefront of medical practice and medical training [35].

\subsection{Causal analysis $\left(t_{1}\right)$}

As presented in Figure 3, the causal paths inferred from the conceptual framework were tested anew $\left(\mathrm{t}_{1}\right)$ by assessing the path coefficients $(\beta)$ estimated by the SEM procedure. First, reassessing the measurement model provided results that were similar with the initial assessment $\left(\mathrm{t}_{0}\right)$. Second, as indicated by the strength and significance of the $\beta s$ and the proportion of explained variance $\left(\mathrm{R}^{2}\right)$, the performance of the theoretical model was found in the replication study to be as good as in the initial study (cf. Figure 2).

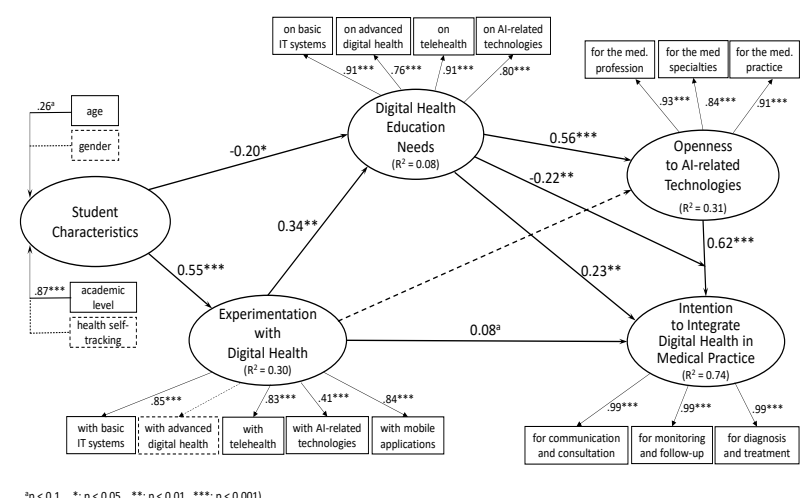

Figure 3. Retest of the Theoretical Model

These last results thus provide further confirmation of the validity and predictive ability of our explanatory model of medical students' needs, attitudes, and intentions about integrating dHealth into their future practice. Moreover, the advent of the Covid-19 pandemic appears to have had no impact on the theorized relationships between the research constructs (causal paths), as replicating the causal analysis produced results quite similar to those observed in the initial causal analysis $\left(\mathrm{t}_{0}\right)$, that is, in terms of the strength and significance of these relationships. 


\section{Discussion}

This exploratory study has significant implications for medical informatics research in that it empirically tested a theoretical model to provide a clear and parsimonious explanation of medical students' intention to integrate dHealth technologies into their future practice. A methodological implication lies in the grouping of individual dHealth technologies and applications into five distinct bundles, which allowed us to identify the experiential learning and education needs of the students with regard to dHealth in a concise yet powerful manner. This allowed us to identify the strengths and weaknesses of the medical curriculum as it pertains to developing the students' dHealth competencies.

The main implication of these findings is that if medical students are to develop the capacity to incorporate dHealth technologies into their future medical practice and exploit these technologies to their fullest potential, they must first be allowed to experiment with these technologies in the course of their medical education, and with AI-related technologies in particular. In other words, in the new health care world brought about by the Covid-19 pandemic, dHealth literacy and self-efficacy are competencies now required not only of physicians and patients but also of medical students [12]. It is worth noting, however, that these competencies do not appear explicitly in the CanMEDS framework, and that the dHealth education provided to Canadian medical students may not fully answer their actual needs in this regard [9, 21]. Moreover, medical education should enable students to develop, in collaboration with their teaching physicians, other health care professionals and patients, innovative digital solutions in support of their role as healthcare providers, be it at present or in the future [36, 37].

This study's results have additional implications for institutional actors in the development and deployment of dHealth technologies in Canada, as they seek to guide and support medical schools in their assimilation of these technologies within the medical curriculum. Thus, healthcare institutions could collaborate on developing and implementing an evidence standards framework for dHealth technologies, similar to the one developed in the United Kingdom by the National Institute for Health and Care Excellence [38]. This would enable a more agile evaluation of these technologies in medical school settings, as well as render them more meaningful to students and add value to dHealth education.

\subsection{Contribution to theory}

All in all, we found the sampled students to have had little occasion to experiment with dHealth technologies and applications in the course of their medical studies.
This may explain why they are rather uncertain as to their dHealth education needs, and in turn why their attitude toward the use of AI-related technologies is rather ambiguous. Now, as predicted by our theoretical model, the combination of these three factors clearly explains why medical students are rather uncertain as to their eventual integration of dHealth into their medical practice $\left(R^{2}{ }_{t 0}=0.66, R^{2}{ }_{t 1}=0.74\right)$. These factors thus constitute important descriptive, predictive, and explanatory keys upon which to reflect on the issue of dHealth education and training in Canadian medical schools, keeping in mind the ultimate goal of improving the quality of healthcare services provided to the population by physicians.

The proposed model may thus constitute an initial conceptual framework for researchers and practitioners concerned with informing, motivating, and preparing medical students to make effective use of dHealth technologies, in general, and of AI-related technologies, in particular. In this regard, it appears that the emphasis on basic IT systems such as EHRs still remains, whereas telehealth appears to have taken on added importance with the advent of the Covid-19 pandemic. Furthermore, as the students' future use of dHealth technologies is determined above all by their having an open attitude on the role of AI in modern medicine, it ensues that the introduction of AI training in medical education should be further investigated [39].

\subsection{Contribution to practice}

This study also makes a significant contribution to dHealth practice by providing medical schools with a conceptual template with which to make a strategic assessment of their dHealth situation and thus obtain actionable insights as to the technologies to be included in the curriculum. The study's findings also allow us to make the following recommendations to Canadian medical schools wishing to better serve their students through the mindful integration of dHealth within the curriculum:

- integrate dHealth training as part of the doctorate in medicine, from the preparatory year;

- create one or several specialized diplomas in dHealth (e.g., telemedicine; AI in health);

- set-up a working group within each faculty of medicine, comprised of professors and students of all levels, to periodically review dHealth training needs in light of existing and emerging technologies;

- periodically assess students' satisfaction with their dHealth training, and make the necessary adjustments; and

- foster collaboration and exchange between medical students and those from other faculties (e.g., computer science, software engineering) interested in dHealth 
technologies through the organization of "hacking health" type of events or symposiums.

Similarly, the following recommendations can be made to the institutions that support and counsel Canadian medical schools such as the AFMC and CMA:

- introduce within the CanMEDS framework [9] competencies that are related to the use of dHealth technologies in modern medicine;

- implement the dHealth competencies previously defined by the AFMC in partnership with Canada Health Infoway;

- highlight and publicize expert reports, guidelines, or white papers related to dHealth published by recognized researchers and institutions;

- set-up a working group to update the dHealth competencies to be acquired in light of technological developments in this field; and

- promote the offer of continuous dHealth training in internship (hospital) settings.

\section{Limitations and Conclusion}

The results of this study must be interpreted with some caution due to its inherent limitations. Given the nature of the sample, its representativeness in relation to all Canadian medical students limits the scope of these results. Future research could investigate the nature and scope of dHealth training offered in medical schools located elsewhere in Canada as well as in other countries and compare students' level of proficiency in dHealth as well as their intention to integrate dHealth technologies in their medical practice. It would also be important to conduct a replication study once the Covid-19 pandemic is behind us. Moreover, the rather low response rate may have induced a non-response bias that is hard to evaluate [37]. Notwithstanding our aim for parsimony, the theoretical model could also be extended in future research by re-including subjective norm to be more comparable to the previously cited TPB/TAM/ UTAUT-based behavioral studies [32,33]. Further, one could include, in addition to dHealth technologies and applications, the IT-enabled medical knowledge management capabilities such as e-healthcare intelligence and e-collaboration that students must develop to practice modern medicine and be both innovative and effective in their future practice [40, 41].

In answering its research questions, our empirical investigation was able to provide a better understanding of the manner in which and the extent to which medical students intend to integrate dHealth into their future medical practice. Based upon a multi-theory behavioral model, the results of this study have revealed the specific dHealth technologies and applications that could be inserted in the medical curriculum to encourage and facilitate students' adoption and assimilation of these technologies, with a particular importance placed upon AI-related technologies. Medical schools and faculties will be asked to do more and better with regard to preparing their students for the effective use of dHealth technologies and applications in their medical practice. It thus behooves them to develop their dHealth education resources and capabilities in coherence with this imperative.

\section{References}

[1] Canadian Medical Association (2018). The Future of Technology in Health and Health Care: A Primer, retrieved from https://www.cma.ca/sites/default/files/ pdf/health-advocacy/activity/2018-08-15-futuretechnology-health-care-e.pdf.

[2] Chandrashekar, P. (2019). A digital health preclinical requirement for medical students. Academic Medicine, 94(6), 749.

[3] Waseh, S. and Dicker, A.P. (2019). Telemedicine training in undergraduate medical education: Mixed-methods review. JMIR Medical Education, 5(1):e12515.

[4] Gaglani, S.M. and Topol, E.J. (2014). iMedEd: The role of mobile health technologies in medical education. Academic Medicine, 89(9), 1207-1209.

[5] Forman, T.M., Armor, D.A. and Miller, A.S. (2019). A review of clinical informatics competencies in nursing to inform best practices in education and nurse faculty development. Nursing Education Perspectives, 41(1), e3e7.

[6] Edirippulige, S., Brooks, P., Carati, C., Wade, V.A., Smith, A.C., Wickramasinghe, S. and Armfield, N.R. (2018). It's important, but not important enough: eHealth as a curriculum priority in medical education in Australia. Journal of Telemedicine and Telecare, 24(10), 697-702.

[7] Lam, M. K., Hines, M., Lowe, R., Nagarajan, S., Keep, M., Penman, M. and Power, E. (2016). Preparedness for eHealth: Health sciences students' knowledge, skills, and confidence. Journal of Information Technology Education: Research, 15, 305-334.

[8] Mostaghimi, A., Olszewski, A. E., Bell, S. K., Roberts, D. H. and Crotty, B. H. (2017). Erosion of digital professionalism during medical students' core clinical clerkships. JMIR Medical Education, 3(1), e9.

[9] Frank, J.R., Snell, L and Sherbino, J. (2015). CanMEDS 2015 Physician Competency Framework. Ottawa: Royal College of Physicians and Surgeons of Canada.

[10] Bhyat, R. (2019). Integrating digital health into medical education. Canadian Family Physician, 65, 683.

[11] Canadian Medical Association (2019). Virtual care in Canada: Discussion paper, retrieved from https://www.cma.ca/sites/default/files/pdf/News/Virtual_ Care_discussionpaper_v2EN.pdf.

[12] Peek N., Sujan M., Scott P. (2020) Digital health and care in pandemic times: impact of COVID-19. BMJ Health Care \& Informatics, 27:e100166.

[13] Delanoë, A., Lépine, J., Turcotte, S., Leiva Portocarrero, M.E., Robitaille, H., Giguère, A.M., Wilson, B.J., Witteman, H.O., Lévesque, I., Guillaumie, L., Légaré, F. 
(2016). Role of psychosocial factors and health literacy in pregnant women's intention to use a decision aid for Down syndrome screening: A theory-based Web survey. Journal of Medical Internet Research, 18(10), 147-164.

[14] Ajzen, I. (2012). The theory of planned behavior. In P.A.M. Lange, A.W. Kruglanski and E.T. Higgins (Eds.), Handbook of Theories of Social Psychology, London, UK: Sage, 438-459.

[15] Venkatesh, V. (2000). Determinants of perceived ease of use: Integrating control, intrinsic motivation, and emotion into the Technology Acceptance Model. Information Systems Research, 11(4), 342-365.

[16] Ngai, E.W.T., Poon, J.K.J. and Chan, Y.H.C. (2007). Empirical examination of the adoption of WebCT using TAM. Computers and Education, 48, 250-267.

[17] Teo, T. (2010). Examining the influence of subjective norm and facilitating conditions on the intention to use technology among pre-service teachers: a structural equation modeling of an extended technology acceptance model. Asia Pacific Education Review, 11, 253-262.

[18] Zahra, S.A. and George, G. (2002). Absorptive capacity: A review, reconceptualization, and extension. Academy of Management Review, 27(2), 185-203.

[19] Lowik, S., Kraaijenbrink, J. and Groen, A.J. (2017). Antecedents and effects of individual absorptive capacity: a micro-foundational perspective on open innovation. Journal of Knowledge Management, 21(6), 1319-1341

[20] Banerjee, R., George, P., Priebe, C. and Alper, E. (2015). Medical student awareness of and interest in clinical informatics. Journal of the American Medical informatics Association, 22:e42-e47.

[21] Aungst TD, Patel R. (2020) Integrating digital health into the curriculum - Considerations on the current landscape and future developments. Journal of Medical Education and Curricular Development, 7:1-7.

[22] Machleid F, Kaczmarczyk R, Johann D, Balčiūnas J, Atienza-Carbonell B, von Maltzahn F., Mosch L. (2020) Perceptions of digital health education among European medical students: mixed methods study. Journal of Medical Internet Research, 22(8):e19827.

[23] Podsakoff, P.M. MacKenzie, S.B. Lee, J.Y. Podsakoff, N.P. (2003). Common method biases in behavioral research: a critical review of the literature and recommended remedies. Journal of Applied Psychology, 88 (5), 879-903.

[24] Pavlou, P.A. Liang, H. and Xue, Y. (2007). Understanding and mitigating uncertainty in online exchange relationships: A principal-agent perspective, MIS Quarterly, 31(1), 105-136.

[25] Lowry, P.B. and Gaskin, J. (2014). Partial least squares (PLS) structural equation modeling (SEM) for building and testing behavioral causal theory: When to choose it and how to use it. IEEE Transactions on Professional Communication, 57(2), 123-146.

[26] Gefen D., Ringdon, E.E. and Straub, D. (2011). An update and extension to SEM guidelines for administrative and social science research. MIS Quarterly, 35 (2), iii-xiv.

[27] Ringle C.M., Sarstedt, M. and Straub D. (2012). A critical look at the use of PLS-SEM in MIS Quarterly. MIS Quarterly, 36(1), iii-xiv.
[28] Diamantopoulos, A. and Siguaw, J. (2006). Formative vs. reflective indicators in organizational measure development: a comparison and empirical illustration. British Journal of Management, 17(4), 263-282.

[29] Hair, J.F., Hult, G.T.M., Ringle, C.M. and Sarstedt, M. (2017). A Primer on Partial Least Squares Structural Equation Modeling (PLS-SEM). Second Edition. Thousand Oaks, California: Sage Publications, 2017.

[30] MacKenzie, S.B., Podsakoff, P.M. and Jarvis, CB. (2005). The problem of measurement model misspecifcation in behavioral and organizational research and some recommended solutions. Journal of Applied Psychology, 90(4), 710-730.

[31] Wang, W., Liu, L., Feng, Y. and Wang, T. (2014). Innovation with IS usage: individual absorptive capacity as a mediator. Industrial Management \& Data Systems, 114(8), 1110-1130.

[32] Venkatesh, V. Thong, J.Y.L. and Xu, X. (2012). Consumer acceptance and use of information technology: extending the unified theory of acceptance and use of technology. MIS Quarterly, 36(1), 157-178.

[33] Jackson, C.M., Chow, S. and Leitch, R.A. (1997). Toward an understanding of the behavioral intention to use an information system. Decision Sciences, 28(2), 357-389.

[34] La Barbera, F. and Ajzen, I. (2021). Moderating role of perceived behavioral control in the theory of planned behavior. Journal of Theoretical Social Psychology, 5, 3545.

[35] Grenier Ouimet, A., Wagner, G., Raymond, L. and Paré, G. (2020). Investigating patient continuance of teleconsultation to anticipate post-crisis momentum: Survey study. Journal of Medical Internet Research, 22(11):e22081.

[36] Paranjape, K., Schinkel, M., Panday, R.N., Car, J. and Nanayakkara, P. (2019). Introducing artificial intelligence training in medical education. JMIR Medical Education, 5(2): e16048.

[37] Phillips, A. W., Friedman, B. T., Utrankar, A., Ta, A. Q., Reddy, S. T. and Durning, S. J. (2017). Surveys of health professions trainees: Prevalence, response rates, and predictive factors to guide researchers. Academic Medicine, 92(2), 222-228.

[38] NICE. (2019) Evidence Standards Framework for Digital Health Technologies. London, UK: National Institute for Health and Care Excellence (www.nice.org.uk/Media/Default/About/what-we-do/ourprogrammes/evidence-standards-framework/digitalevidence-standards-framework.pdf.

[39] Pinto Dos Santos, D., Giese, D., et al. (2019). Medical students' attitude towards artificial intelligence: a multicentre survey. European Radiology, 29(4), 16401646.

[40] Brunner, M., McGregor, D., Keep, M., et al. (2018). An eHealth capabilities framework for graduates and health professionals: mixed-methods study. Journal of Medical Internet Research, 20(5), e10229.

[41] Raymond, L., Paré, G. and Maillet, É. (2017). IT-based clinical knowledge management in primary health care: A conceptual framework. Knowledge and Process Management, 24(4), 247-256 